\title{
Grundkurs „Künstliche Intelligenz in der Neuroradiologie“
}

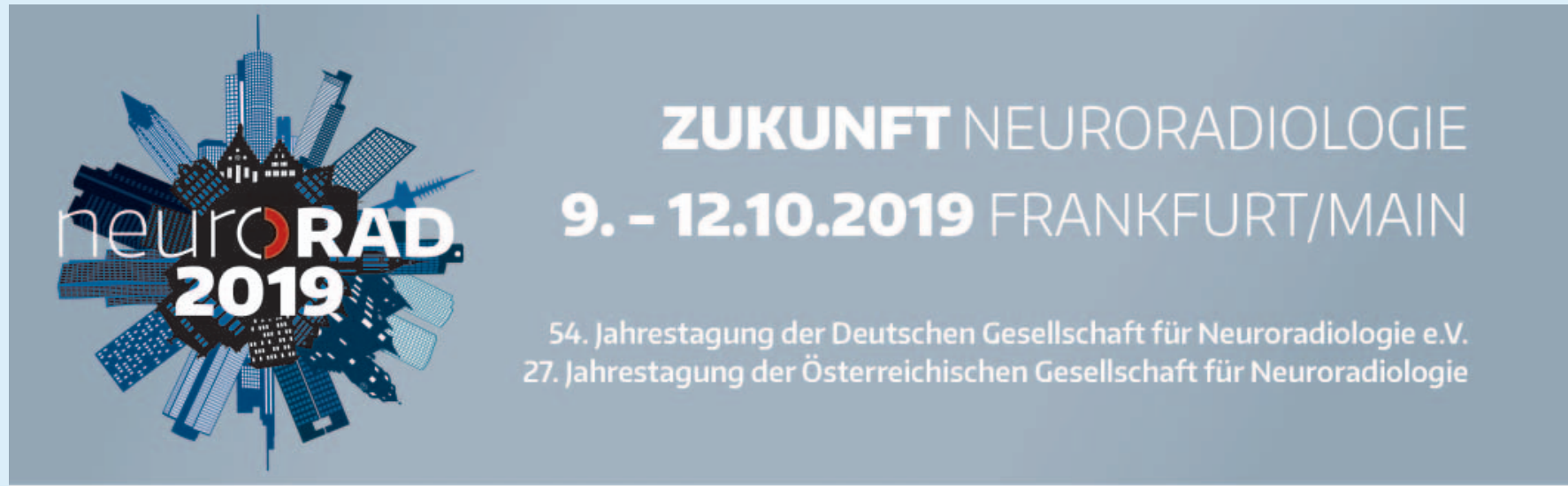

Die Begriffe „Künstliche Intelligenz“ und „Big Data“ bestimmen die aktuellen Diskussionen über die Zukunft des Gesundheitswesens im Allgemeinen und der Radiologie im Speziellen. Bei allen Ungewissheiten, die diesbezüglich bestehen, bietet die Thematik großes Potential für die Verbesserung der Patientenversorgung. Sie ermöglicht insbesondere der radiologischen Gemeinschaft, eine Vorreiterrolle bei der Anwendung entsprechender Techniken einzunehmen.
Es ist heutzutage also unerlässlich, ein Grundverständnis für Prinzipien des maschinellen Lernens und resultierende computergestützte Entscheidungssysteme zu entwickeln, um diese erfolgreich im klinischen Betrieb einzusetzen.

Aus diesem Grund bieten wir auf dem neuroRAD 2019 erstmals den „Grundkurs Künstliche Intelligenz in der Neuroradiologie“ an.
Renommierte nationale und internationale Spezialisten vermitteln Ihnen ein Grundverständnis für die Prinzipien des maschinellen Lernens - und dies praxistauglich und anhand klarer Lernziele. Vorkenntnisse sind nicht erforderlich!

Sichern Sie sich jetzt einen der wenigen Plätze und seien Sie am Puls der Zeit!

Das Programm sowie die Anmeldung finden Sie unter neurorad.de $>$ Programm. 